\title{
Correction to: A Modern Approach to Personalize Exergames for the Physical Rehabilitation of Children Suffering from Lumbar Spine
}

Cristian Gómez-Portes (D), Carmen Lacave (D), Ana I. Molina (D), David Vallejo (1), and Santiago Sánchez-Sobrino (D)

\section{Correction to:}

Chapter "A Modern Approach to Personalize Exergames

for the Physical Rehabilitation of Children Suffering

from Lumbar Spine" in: J. Filipe et al. (Eds.):

Enterprise Information Systems, LNBIP 417, https://doi.org/10.1007/978-3-030-75418-1_35

In the originally published version of chapter 35 , the special characters in the names of Cristian Gómez-Portes and Santiago Sánchez-Sobrino had been left out initially due to conversion errors. This has been corrected. 